\title{
HASIL BELAJAR PAI MELALUI METODE COOPERATIVE SCRIPT \& MAKE A MATCH DI SMPN 1 SALATIGA
}

\author{
Nurhayati Ekasari \\ IAIN Salatiga \\ nurhayatiekasari@yahoo.com
}

\begin{abstract}
Abstrak
Penelitian ini bertujuan untuk meningkatkan hasil belajar PAI materi Iman Kepada Malaikat-Malaikat Allah Melalui Metode Cooperative Script dan Make a Match di SMP Negeri 1 Salatiga. Penelitian ini merupakan Penelitian Tindakan Kelas dengan tahapan perencanaan, pelaksanaan, observasi, dan refleksi.Teknik pengumpulan data yang digunakan observasi, tes, dan dokumentasi. Data yang diperoleh berupa hasil tes formatif, nilai praktik, dan lembar observasi kegiatan pembelajaran. Kemudian dianalisis menggunakan rumus ketuntasan individu dan ketuntasan klasikal kemudian ditarik kesimpulan. Hal ini dibuktikan dari peningkatan pada setiap siklusnya. Pada kegiatan pra siklus siswa yang tuntas sebanyak 5 siswa atau 26,3\% dan 14 siswa lainnya atau 73,7\% belum tuntas. Pada kegiatan siklus I sebanyak 9 siswa atau 47,4\% dan 10 siswa atau 52,6\% belum tuntas. Pada kegiatan siklus II menjadi 17 siswa atau $89,5 \%$ dan 2 siswa atau 10,5\% belum tuntas. Maka siklus II ini telah dikatakan berhasil dengan menggunakan metode Cooperative Script dan Make A Match.
\end{abstract}

Kata Kunci: Hasil Belajar, PAI, dan Metode

Abstract

This study aims to improve the learning outcomes PAI of Faith in the Angels of God through the Cooperative Script Method and Make a Match in SMP Negeri 1 Salatiga.This research is a Classroom Action Research with stages of planning, implementation, observation, and reflection. Data collection techniques used observation, tests, and documentation. The data obtained in the form of formative test results, practice scores, and observation sheets of learning activities. Then analyzed using individual completeness formulas and classical completeness then drawn conclusions.This is evidenced by the increase in each cycle. In the pre-cycle activities of students who completed as many as 5 students or $26.3 \%$ and 14 other students or $73.7 \%$ had not been completed. In the first cycle of 9 students or $47.4 \%$ and 10 students or $52.6 \%$ had not been completed. In cycle II activities there were 17 students or $89.5 \%$ and 2 students or $10.5 \%$ were not finished. So this second cycle has been said to be successful using the Cooperative Script method and Make A Match.

Keyword: Learning Outcomes, PAI, and Method

\section{A. PENDAHULUAN}

Pendidikan adalah sebuah usaha untuk mengembangkan potensi peserta didik agar memiliki kemampuan untuk berbaur dengan masyarakat [6]. Sedangkan Badrus Zaman mendefinisikan Pendidikan adalah proses suatu bangsa mempersiapkan generasi mudanya untuk menjalankan kehidupan dan untuk memenuhi tujuan hidup secara efektif dan efisien [10]. Pendidikan juga adalah suatu proses suatu bangsa atau negara membina dan mengembangkan kesadaran diri diantara individu-individu [9].

Menurut Zakiah Daradjat pendidikan Agama Islam merupakan sebuah usaha bimbingan kepada peserta didik agar kelak ia menjadi pribadi yang lebih bermoral dengan tidak melanggar norma-norma yang sudah berlaku [2]. Menurut Achmadi pendidikan agama Islam adalah suatu usaha lebih khusus ditekankan untuk mengembangkan fitrah keberagaman dan sumber daya insani agar mampu memahami, menghayati, dan mengamalkan ajaran-ajaran Islam [4]. Pendidikan yang dilaksanakan pada prinsipnya semua sama, yaitu memberi bimbingan agar dapat hidup mandiri sehingga dapat meneruskan dan melestarikan tradisi yang hidup di masyarakat [9]. Berdasarkan pernyataan di atas dapat disimpulkan bahwa pendidikan agama Islam merupakan upaya sadar dan 
terencana dalam menyiapkan peserta didik untuk mengenal, memahami, menghayati hingga mengimani serta mengamalkan ajaran agama Islam dengan kesadaran nilai-nilai moralitas yang dilakukan dengan perbuatan atau perilaku seseorang.

Belajar merupakan suatu proses untuk mengajarkan hal-hal baru agar menjadi panutan untuk kehidupan yang lebih terarah [8]. Menurut Hilgrad dan Bower belajar merupakan suatu proses memberi pengetahuan yang diperoleh melalui pengalaman, mengingat, dan mendapatkan informasi atau menemukan hal baru [3]. Menurut Klein belajar sebagai hasil yang memberikan perubahan pada perilaku dan sikap yang menjadikan pribadi yang bertanggung jawab [5]. Jadi dapat disimpulkan bahwa belajar adalah suatu aktivitas yang dilakukan seseorang dengan sengaja dalam keadaan sadar untuk memperoleh suatu konsep, pemahaman atau pengetahuan baru sehingga memungkinkan terjadinya perubahan perilaku baik dalam berpikir dan bertindak seseorang.

Mata pelajaran Pendidikan Agama Islam materi Iman kepada Malaikat-Malaikat Allah SWT banyak siswa yang mengalami kesulitan. Hal ini dibuktikan dengan hasil belajar siswa yang kurang memuaskan ketika dilihat dari nilai tugas dan nilai ulangan. Berdasarkan hasil observasi pada tanggal 28 Januari tahun 2020 maka didapatkan hasil belajar siswa kelas VII G SMP Negeri 1 Salatiga hanya 5 siswa yang memenuhi KKM dan 14 siswa yang belum mencapai KKM. Dari data di atas dapat disimpulkan bahwa 73,7\% siswa kelas VII G hasil belajar materi Iman kepada Malaikat-Malaikat Allah SWT masih rendah.

Berdasarkan hasil observasi pada tanggal 16 September tahun 2019 hasil belajar siswa masih rendah karena dipengaruhi oleh beberapa faktor diantaranya dari siswa maupun dari pendidik. Adapun dari faktor siswa, mereka memiliki hasil belajar yang kurang maksimal dikarenakan kurangnya minat membaca buku terhadap materi agama khususnya, selain itu siswa tersebut hanya mengikuti pembelajaran di sekolah. Sewaktu di rumah, tidak mengulang kembali materi yang sudah diajarkan di sekolah dan tidak diikutkan TPA (Taman Pendidikan Al Qur'an) oleh orang tuanya. Jadi pengetahuan mereka terbatas pada saat di kelas. Sedangkan dari faktor pendidik, pada saat observasi dalam pembelajaran menggunakan metode konvensional seperti ceramah dan cerita sehingga siswa kurang tertarik dan merasa bosan dengan pembelajaran tersebut karena metode yang diterapkan kurang menyenangkan dan kurangnya informasi tentang model dan metode-metode pembelajaran sehingga pendidik hanya menggunakan metode konvensional dalam proses pembelajaran. Seorang pendidik juga kurang memaksimalkan fasilitas yang ada karena pendidik tersebut kurangnya informasi tentang teknologi. Proses pembelajaran yang kurang menarik dan monoton dapat mempengaruhi hasil belajar siswa.

Berdasarkan uraian di atas dapat diartikan bahwasanya kedudukan daripada metode pembelajaran itu sendiri, mempunyai peran yang begitu penting guna mencapai hasil belajar atau prestasi belajar yang maksimal bagi peserta didik sesuai dengan yang diharapkan. Untuk itu, peneliti bermaksud meneliti masalah tersebut dengan melakukan Penelitian Tindakan Kelas (PTK), yaitu dengan memperbaiki proses pembelajaran serta meningkatkan hasil belajar peserta didik pada mata pelajaran PAI dengan menggunakan metode Cooperative Script dan metode Make A Match. Metode Cooperative Script dan metode Make A Match itu sendiri adalah sebuah metode yang mampu menarik minat peserta didik dan mampu memancing kreatifitas peserta didik itu sendiri. Metode pembelajaran ini akan diterapkan peneliti melalui penelitian tindakan kelas.

Berdasarkan latar belakang masalah yang telah dijelaskan di atas, perumusan masalah dalam hal ini: Apakah penerapan metode Cooperative Script dan Make A Match dapat meningkatkan hasil belajar Pendidikan Agama Islam materi Iman kepada Malaikat-Malaikat Allah SMP Negeri 1 Salatiga. Data penelitian diambil dalam proses pembelajaran satu semester pada tahun pelajaran 2019/2020.

Adapun tujuan penelitian yaitu untuk mendeskripsikan peningkatan hasil belajar Pendidikan Agama Islam materi Iman kepada Malaikat-Malaikat Allah SWT melalui metode Cooperative Script dan Make A Match SMP Negeri 1 Salatiga Tahun Pelajaran 2019/2020. 


\section{B. METODE PENELITIAN}

Rancangan penelitian yang diterapkan berupa penelitian tindakan kelas (PTK). Penelitian tindakan kelas adalah penelitian yang memaparkan terjadinya sebab akibat dari perlakuan, sekaligus memaparkan apa saja yang terjadi ketika perlakuan diberikan dan memaparkan seluruh proses sejak awal pemberian perlakuan sampai dengan dampak dari perlakuan tersebut [1]. Penelitian tindakan kelas ini dipilih untuk memecahkan permasalahan yang ditemukan dalam proses pembelajaran Pendidikan Agama Islam dan budi pekerti. Rendahnya hasil belajar siswa dapat dianalisa menggunakan jenis penelitian tindakan kelas. Setelah penyebab masalah ditemukan, selanjutnya melakukan tindakan yang dianggap mampu memecahkan masalah tersebut.Pada akhir tindakan dilakukan refleksi tentang keberhasilan dan kegagalan tindakan terhadap pemecahan masalah.

Penelitian ini menekankan terhadap pemahaman materi menggunakan metode Cooperative Script dan metode Make A Match dilakukan setelah mengetahui adanya permasalahan dalam hasil belajar peserta didik kelas VII G di SMP Negeri 1 Salatiga yang sebagian besar belum mencapai KKM yang ditentukkan. Teknik pengumpulan data yang digunakan observasi, tes, dan dokumentasi.

Tahapan Penelitian Tindakan kelas ini adalah model Kemmis dan Mc Taggart yang memperkenalkan empat tahap dalam pelaksanaan metode penelitian tindakan, yaitu: Perencanaan (planning), Tindakan (acting), Observiasi (observing) dan Refleksi (reflecting). Secara rinci prosedur pelaksanaan PTK ini dapat digunakan sebagai berikut:

Siklus 1

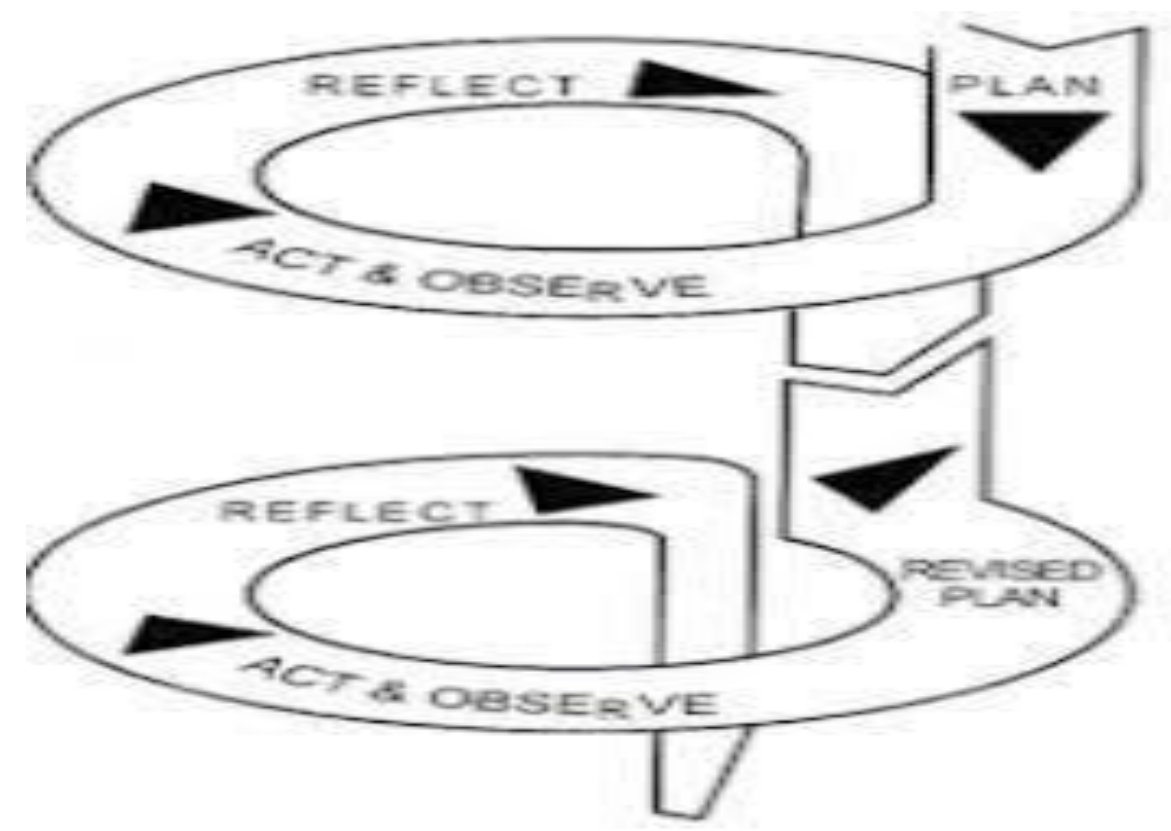

Gambar 1.1 Siklus dalam prosedur PTK [7].

\section{HASIL DAN PEMBAHASAN}

1. Deskripsi Data Pra Siklus

Sebelum diadakan kegiatan pada siklus-siklus penelitian terlebih dahulu dilakukan kegiatan pra siklus.Pada penelitian ini digunakan nilai hasil ulangan harian yang didapatkan dari guru pengampu mata pelajaran Pendidikan Agama Islam dan Budi Pekerti.Kegiatan pra siklus ini dilaksanakan pada hari Rabu, 13 November 2019.Guru hanya menggunakan metode 
konvensional pada saat mengajar seperti ceramah dan kurang memaksimalkan fasilitas yang telah disediakan oleh sekolah. Oleh karena itu dapat menyebabkan kurangnya pemahaman siswa terhadap materi yang diajarkan.Peneliti sendiri menggunakan indikator keberhasilan untuk dijadikan sebagai alat ukur keberhasilan dalam belajar yaitu yaitu KKM mata pelajaran Iman Kepada Malaikat-Malaikat Allah SMP Negeri 1 Salatiga sebesar 80, serta dengan menggunakan Kriteria Ketuntasan Klasikal (KKL), yakni sebesar 85\%. Dalam Pra Siklus, peneliti menggunakan data nilai ulangan terakhir peserta didik.

Data pra siklus siswa kelas VII G SMP Negeri 1 Salatiga adalah sebagai berikut: Tabel 4.1 Data Pra Siklus

\begin{tabular}{l|lll} 
No. & Nama Siswa & Nilai & Keterangan \\
\hline 1 & Siswa 1 & 88 & Tuntas \\
2 & Siswa 2 & 74 & Tidak Tuntas \\
3 & Siswa 3 & 76 & Tidak Tuntas \\
4 & Siswa 4 & 71 & Tidak Tuntas \\
5 & Siswa 5 & 62 & Tidak Tuntas \\
6 & Siswa 6 & 69 & Tidak Tuntas \\
7 & Siswa 7 & 74 & Tidak Tuntas \\
8 & Siswa 8 & 74 & Tidak Tuntas \\
9 & Siswa 9 & 81 & Tuntas \\
10 & Siswa 10 & 76 & Tidak Tuntas \\
11 & Siswa 11 & 78 & Tidak Tuntas \\
12 & Siswa 12 & 93 & Tuntas \\
13 & Siswa 13 & 75 & Tidak Tuntas \\
14 & Siswa 14 & 54 & Tidak Tuntas \\
15 & Siswa 15 & 84 & Tuntas \\
16 & Siswa 16 & 64 & Tidak Tuntas \\
17 & Siswa 17 & 68 & Tidak Tuntas \\
18 & Siswa 18 & 72 & Tidak Tuntas \\
19 & Siswa19 & 81 & Tuntas \\
& Jumlah & 1.414 & \\
& Rata-Rata & 74,4 &
\end{tabular}

Berdasarkan data tersebut dapat disimpulkan bahwa siswa yang tuntas sebanyak 5 siswa atau $26,3 \%$ sedangkan siswa yang tidak tuntas sebanyak 14 siswa atau $73,7 \%$. Nilai tersebut menunjukkan secara klasikal nilai pembelajaran siswa belum memenuhi kriteria ketuntasan.Dengan hasil pengamatan kondisi awal ini maka dilaksanakan serangkaian perencanaan tindakan kelas guna mengatasi hambatan-hambatan tersebut yang diakhiri pada sebuah kegiatan refleksi.

2. Deskripsi Siklus 1

Pada bagian siklus I ini untuk mengetahui hasil belajar Pendidikan Agama Islam dan Budi Pekerti pada siswa kelas VII G SMP Negeri 1 Salatiga dengan menggunakan metode Cooperative Script dan Make A Match pada materi Iman kepada Malaikat-Malaikat Allah SWT. Tahapan dan langkah-langkah yang dilakukan meliputi perencanaan, pelaksanaan, observasi, dan refleksi.

\section{a. Hasil Tes}

Pelaksanaan siklus I ini digunakan metode Cooperative Script dan Make A Match pada proses pembelajaran Pendidikan Agama Islam materi Iman Kepada Malaikat-Malaikat 
Allah SWT yang dilaksanakan pada hari Rabu, 8 Januari 2020. Adapun data siklus I siswa kelas VII G SMP Negeri 1 Salatiga adalah sebagai berikut:

Tabel 4.2 Data Siklus I

\begin{tabular}{l|lll} 
No. & Nama Siswa & Nilai & Keterangan \\
\hline 1 & Siswa 1 & 87 & Tuntas \\
2 & Siswa 2 & 70 & Tidak Tuntas \\
3 & Siswa 3 & 70 & Tidak Tuntas \\
4 & Siswa 4 & 77 & Tidak Tuntas \\
5 & Siswa 5 & 70 & Tidak Tuntas \\
6 & Siswa 6 & 95 & Tuntas \\
7 & Siswa 7 & 84 & Tuntas \\
8 & Siswa 8 & 80 & Tuntas \\
9 & Siswa 9 & 65 & Tidak Tuntas \\
10 & Siswa 10 & 84 & Tuntas \\
11 & Siswa 11 & 50 & Tidak Tuntas \\
12 & Siswa 12 & 95 & Tuntas \\
13 & Siswa 13 & 80 & Tuntas \\
14 & Siswa 14 & 65 & Tidak Tuntas \\
15 & Siswa 15 & 60 & Tidak Tuntas \\
16 & Siswa 16 & 62 & Tidak Tuntas \\
17 & Siswa 17 & 65 & Tidak Tuntas \\
18 & Siswa 18 & 82 & Tuntas \\
19 & Siswa 19 & 84 & Tuntas \\
& Jumlah & 1.425 & \\
& Rata-Rata & 75 &
\end{tabular}

Apabila mengamati hasil evaluasi dari siklus I sudah ada peningkatan hasil belajar dibandingkan dengan hasil evaluasi dari pra siklus. Hasil rata-rata evaluasi meningkat dari 74,4 menjadi 75 dan presentase ketuntasan dari $26,3 \%$ menjadi $47,4 \%$. Pada siklus I masih terdapat 10 siswa yang belum tuntas dari KKM yang telah ditetapkan yaitu 80.Maka dari itu dilakukan siklus II untuk meningkatkan pemahaman siswa terhadap materi pembelajaran.

b. Lembar Pengamatan Guru Siklus 1

Tabel 4.4 Lembar Observasi Guru

No Aspek yang Diamati

I. Pra Pembelajaran

1. Kesiapan ruang dan alat pembelajaran

2. Memeriksa kesiapan siswa

II. Kegiatan Membuka Pembelajaran

3. Kesesuaian kegiatan apersepsi dengan materi ajar

4. Menyampaikan kompetensi (tujuan yang akan dicapai)

III. Kegiatan Inti Pembelajaran

A. Penguasaan Materi Pembelajaran

\section{Skala}

Partisipasi

YA TIDAK

$\sqrt{ }$

$\sqrt{ }$

$\sqrt{ }$

$\sqrt{ }$ 
5. Menunjukkan penguasaan materi pembelajaran $\quad \sqrt{ }$

6. Menyampaikan materi dengan jelas

7. Guru menyampaikan semua tujuan pembelajaran yang dicapai

B. Metode Cooperative Script dan Make A Match

8. Guru memberikan garis besar tentang materi tersebut $\sqrt{ }$

9. Guru menjelaskan metode Cooperative Script dan Make A $\sqrt{ }$ Match

10. Guru menyampaikan peraturan dan tata cara pembelajaran $\sqrt{ }$ yang akan dilaksanakan

11. Guru membagi siswa menjadi berpasangan

12. Guru menyiapkan beberapa kartu yang kemudian masingmasing anak mengambil kartu tersebut

13. Guru mengintruksikan kepada siswa untuk mencari $\sqrt{ }$ pasangan dari kartu yang dipegang

14. Guru mencatat siswa yang belum dapat pasangan setelah waktu habis dan siswa yang berhasil untuk diberi point

15. Guru menunjuk siswa untuk mempresentasikan kartu bersama pasangannya,

16. Guru memberikan soal evaluasi

C. Pembelajaran yang Memicu dan Memelihara Keterlibatan Siswa

17. Menumbuhkan partisipasi aktif dalam pembelajaran $\sqrt{ }$

18. Menunjukkan sikap terbuka terhadap respon siswa

19. Menumbuhkan keceriaan dan antusiasme dalam $\sqrt{ }$ pembelajaran

D. Penilaian Proses dan Hasil Belajar

20. Memantau kemajuan belajar selama proses pembelajaran $\sqrt{ }$

21. Melakukan penilaian akhir sesuai dengan kompetensi $\sqrt{ }$

E. Penggunaan Bahasa

22. Menggunakan bahasa lisan secara jelas dan benar

23. Menyampaikan pesan dengan gaya yang sesuai

IV Penutup

24. Menanyakan hal-hal yang belum diketahui siswa $\sqrt{ }$

25. Melakukan refleksi atau kesimpulan materi pembelajaran $\sqrt{ }$ dengan melibatkan siswa

26. Melakukan tindak lanjut

Adapun dari tabel di atas bahwa terdapat 25 yang mencentang kolom "Ya" atau sebanyak $96,1 \%$ dan terdapat 1 yang mencentang kolom "Tidak". Karena dalam menyampaikan materi, guru tersebut kurang menampilkan bahasa non verbalnya.Karena bahasa non verbal juga perlu digunakan untuk memantapkan penjelasan dari guru.

c. Lembar Pengamatan Peserta Didik

Tabel 4.3Lembar Observasi Siswa

\begin{tabular}{|l|l|l|l|l|}
\hline No & Aspek yang Diamati & \multicolumn{2}{l|}{ Skala Partisipasi } \\
\cline { 3 - 5 } & & YA & TIDAK \\
\hline A. & Kegiatan Awal & \multicolumn{3}{|l|}{} \\
\hline & $\begin{array}{l}\text { 1. Siswa menjawab salam dengan semangat dan } \\
\text { dilanjutkan berdoa }\end{array}$ & $\sqrt{ }$ & \\
\hline
\end{tabular}




\begin{tabular}{|c|c|c|c|}
\hline & 2. Siswa merespon panggilan presensi dari guru & $\sqrt{ }$ & \\
\hline & 3. Siswa menjawab pertanyaan apersepsi dari guru & $\sqrt{ }$ & \\
\hline & $\begin{array}{l}\text { 4. Siswa mendengarkan penjelasan langkah-langkah } \\
\text { pembelajaran yang akan dilaksanakan }\end{array}$ & $\sqrt{ }$ & \\
\hline B. & Kegiatan Inti & & \\
\hline & Eksplorasi & & \\
\hline & $\begin{array}{l}\text { Siswa memperhatikan penjelasan dari guru tentang } \\
\text { metode Cooperative Script dan Make A Match }\end{array}$ & $\sqrt{ }$ & \\
\hline & $\begin{array}{l}\text { 6. Siswa mendengarkan peraturan dan tata cara } \\
\text { pembelajaran yang akan dilaksanakan }\end{array}$ & $\sqrt{ }$ & \\
\hline & Elaborasi & & \\
\hline & $\begin{array}{l}\text { 7. Siswa secara berpasangan untuk mengkomunikasikan } \\
\text { materi }\end{array}$ & $\sqrt{ }$ & \\
\hline & 8. Siswa mengambil satu buah kartu yang telah disediakan & $\sqrt{ }$ & \\
\hline & 9. Setiap siswa mendapat satu buah kartu & $\sqrt{ }$ & \\
\hline & $\begin{array}{l}\text { 10. Setiap siswa memikirkan jawaban atas soal dari kartu } \\
\text { yang dipegang }\end{array}$ & $\sqrt{ }$ & \\
\hline & $\begin{array}{l}\text { 11. Setiap siswa mencari pasangan yang mempunyai kartu } \\
\text { yang cocok dengan kartunya }\end{array}$ & $\sqrt{ }$ & \\
\hline & $\begin{array}{l}\text { 12. Setiap siswa yang dapat mencocokkan kartunya } \\
\text { sebelum batas waktu diberi point }\end{array}$ & $\sqrt{ }$ & \\
\hline & $\begin{array}{l}\text { 13. Setiap siswa yang belum mendapatkan pasangan yang } \\
\text { sesuai dengan kartu maka diberi hukuman }\end{array}$ & $\sqrt{ }$ & \\
\hline & $\begin{array}{l}\text { 14. Siswa bersama pasangannnya mempresentasikan kartu } \\
\text { yang dipegang }\end{array}$ & $\sqrt{ }$ & \\
\hline & 15. Siswa mengerjakan soal yang diberikan oleh guru & $\sqrt{ }$ & \\
\hline & Konfirmasi & & \\
\hline & 16. Siswa berani mengajukan pertanyaan kepada guru & & $\sqrt{ }$ \\
\hline & 17. Siswa mengumpulkan lembar kerja & $\sqrt{1}$ & \\
\hline C. & Penutup & & \\
\hline & 18. Siswa menyimpulkan materi & $\sqrt{ }$ & \\
\hline & 19. Siswa berdoa dan menjawab salam & $\sqrt{ }$ & \\
\hline
\end{tabular}

Berdasarkan tabel tersebut bahwa kolom "Ya" terdapat 18 siswa atau sebanyak 94,7\% dan kolom "tidak" terdapat 1 siswa karena pada siklus I, siswa belum terlalu aktif dalam mengikuti pembelajaran dan banyak siswa juga malu untuk menyampaikan aspirasi mereka ataupun untuk bertanya.

\section{d. Hasil Pengamatan Guru dan Peserta Didik}

Berdasarkan hasil pengamatan dari siklus I terdapat beberapa kelemahan dalam proses pembelajaran sebagai berikut:

1) Siswa kurang memahami materi yang diberikan oleh guru, sehingga dalam mengkomunikasikan materi kepada temannya kurang maksimal.

2) Pada saat mengkomunikasikan materi kepada temannya banyak siswa yang masih bercanda dalam menyampaikan materi tersebut.

3) Dalam mencari pasangan kartu siswa tidak memanfaatkan waktu dengan baik. 
Berdasarkan hasil tersebut, maka hal-hal yang perlu diperbaiki sebagai berikut:

1) Guru lebih tegas pada saat siswa mengkomunikasikan materi kepada temannya.

2) Menambah waktu untuk siswa mempelajari materi agar masing-masing siswa dapat memahami materi tersebut.

3) Guru lebih tegas dalam menerapkan peraturan pada metode Make A Match.

3. Deskripsi Siklus II

Pembelajaran siswa pada siklus II lebih memaksimalkan penerapan metode Cooperative Script dan Make A Match untuk memperbaiki kekurangan yang ada pada siklus I. Guru juga memberikan motivasi untuk membangkitkan semangat belajar siswa. Pada siklus II ini juga diberi soal evaluasi untuk mengukur hasil belajar siswa.

a. Hasil Tes

Siklus II ini dilaksanakan pada hari Rabu, 15 Januari 2020 dengan materi Iman kepada Malaikat-Malaikat Allah SWT melalui metode Cooperative Script dan Make A Match sebagai perbaikan dari siklus I. Adapun hasil evaluasi yang dilakukan terhadap siswa kelas VII G SMP Negeri 1 Salatiga sebagai berikut:

Tabel 4.5 Data Siklus II

\begin{tabular}{l|lll} 
No. & Nama Siswa & Nilai & Keterangan \\
\hline 1 & Siswa 1 & 95 & Tuntas \\
2 & Siswa 2 & 80 & Tuntas \\
3 & Siswa 3 & 100 & Tuntas \\
4 & Siswa 4 & 85 & Tuntas \\
5 & Siswa 5 & 90 & Tuntas \\
6 & Siswa 6 & 95 & Tuntas \\
7 & Siswa 7 & 95 & Tuntas \\
8 & Siswa 8 & 85 & Tuntas \\
9 & Siswa 9 & 70 & Tidak Tuntas \\
10 & Siswa 10 & 90 & Tuntas \\
11 & Siswa 11 & 90 & Tuntas \\
12 & Siswa 12 & 95 & Tuntas \\
13 & Siswa 13 & 80 & Tuntas \\
14 & Siswa 14 & 80 & Tuntas \\
15 & Siswa 15 & 70 & Tidak Tuntas \\
16 & Siswa 16 & 85 & Tuntas \\
17 & Siswa 17 & 80 & Tuntas \\
18 & Siswa 18 & 80 & Tuntas \\
19 & Siswa 19 & 100 & Tuntas \\
& Jumlah & 1.645 & \\
& Rata-Rata & 86,6 &
\end{tabular}

Dari data tersebut menunjukkan bahwa siswa yang tuntas sebanyak 17 siswa atau $89,5 \%$ sedangkan yang tidak tuntas sebanyak 2 siswa atau 10,5\% dan nilai rata-rata kelas sebanyak 85,5. Disimpulkan bahwa pada siklus II dikatakan berhasil karena presentase ketuntasan mencapai $89,5 \%$ dan sudah memenuhi indikator keberhasilan yang harus mencapai $85 \%$. 
b. Hasil Pengamatan Guru Siklus II

Tabel 4.7 Lembar Observasi Guru

\begin{tabular}{|c|c|c|c|}
\hline \multirow[t]{2}{*}{ No. } & \multirow[t]{2}{*}{ Aspek yang Diamati } & \multicolumn{2}{|c|}{ Skala Partisipasi } \\
\hline & & YA & TIDAK \\
\hline \multirow[t]{3}{*}{ I. } & \multicolumn{3}{|l|}{ Pra Pembelajaran } \\
\hline & 1. Kesiapan ruang dan alat pembelajaran & $\sqrt{ }$ & \\
\hline & 2. Memeriksa kesiapan siswa & $\sqrt{ }$ & \\
\hline \multirow[t]{3}{*}{ II. } & \multicolumn{3}{|l|}{ Kegiatan Membuka Pembelajaran } \\
\hline & 3. Kesesuaian kegiatan apersepsi dengan materi ajar & $\sqrt{ }$ & \\
\hline & 4. Menyampaikan kompetensi (tujuan yang akan dicapai) & $\sqrt{ }$ & \\
\hline III. & \multicolumn{3}{|l|}{ Kegiatan Inti Pembelajaran } \\
\hline \multirow[t]{4}{*}{ A. } & Penguasaan Materi Pembelajaran & & \\
\hline & 5. Menunjukkan penguasaan materi pembelajaran & $\sqrt{ }$ & \\
\hline & 6. Menyampaikan materi dengan jelas & $\sqrt{ }$ & \\
\hline & $\begin{array}{l}\text { 7. Guru menyampaikan semua tujuan pembelajaran yang } \\
\text { dicapai }\end{array}$ & $\sqrt{ }$ & \\
\hline \multirow[t]{10}{*}{ B. } & Metode Cooperative Script dan Make A Match & & \\
\hline & 8. Guru memberikan garis besar tentang materi tersebut & $\sqrt{ }$ & \\
\hline & $\begin{array}{l}\text { 9. Guru menjelaskan metode Cooperative Script dan Make } \\
\text { A Match }\end{array}$ & $\sqrt{ }$ & \\
\hline & $\begin{array}{l}\text { 10. Guru menyampaikan peraturan } \\
\text { pembelajaran yang akan dilaksanakan }\end{array}$ & $\sqrt{ }$ & \\
\hline & 11. Guru membagi siswa menjadi berpasangan & $\sqrt{ }$ & \\
\hline & $\begin{array}{l}\text { 12. Guru menyiapkan beberapa kartu yang kemudian masing- } \\
\text { masing anak mengambil kartu tersebut }\end{array}$ & $\sqrt{ }$ & \\
\hline & $\begin{array}{l}\text { 13. Guru mengintruksikan kepada siswa untuk mencari } \\
\text { pasangan dari kartu yang dipegang }\end{array}$ & $\sqrt{ }$ & \\
\hline & $\begin{array}{l}\text { 14. Guru mencatat siswa yang belum dapat pasangan setelah } \\
\text { waktu habis dan siswa yang berhasil untuk diberi point }\end{array}$ & $\sqrt{ }$ & \\
\hline & $\begin{array}{l}\text { 15. Guru menunjuk siswa untuk mempresentasikan kartu } \\
\text { bersama pasangannya. }\end{array}$ & $\sqrt{ }$ & \\
\hline & 16. Guru memberikan soal evaluasi & $\sqrt{ }$ & \\
\hline \multirow[t]{4}{*}{ C. } & \multicolumn{3}{|l|}{ Pembelajaran yang Memicu dan Memelihara Keterlibatan Siswa } \\
\hline & 17. Menumbuhkan partisipasi aktif dalam pembelajaran & $\sqrt{ }$ & \\
\hline & 18. Menunjukkan sikap terbuka terhadap respon siswa & $\sqrt{ }$ & \\
\hline & $\begin{array}{l}\text { 19. Menumbuhkan keceriaan dan antusiasme dalam } \\
\text { pembelajaran }\end{array}$ & $\sqrt{ }$ & \\
\hline \multirow[t]{3}{*}{ D. } & \multicolumn{3}{|l|}{ Penilaian Proses dan Hasil Belajar } \\
\hline & 20. Memantau kemajuan belajar selama proses pembelajaran & $\sqrt{ }$ & \\
\hline & 21. Melakukan penilaian akhir sesuai dengan kompetensi & $\sqrt{ }$ & \\
\hline \multirow[t]{3}{*}{ E. } & \multicolumn{3}{|l|}{ Penggunaan Bahasa } \\
\hline & 22. Menggunakan bahasa lisan secara jelas dan benar & $\sqrt{ }$ & \\
\hline & 23. Menyampaikan pesan dengan gaya yang sesuai & $\sqrt{ }$ & \\
\hline \multirow[t]{4}{*}{ IV } & \multicolumn{3}{|l|}{ Penutup } \\
\hline & 24. Menanyakan hal-hal yang belum diketahui siswa & $\sqrt{ }$ & \\
\hline & $\begin{array}{l}\text { 25. Melakukan refleksi atau kesimpulan materi pembelajaran } \\
\text { dengan melibatkan siswa }\end{array}$ & $\sqrt{ }$ & \\
\hline & 26. Melakukan tindak lanjut & $\sqrt{ }$ & \\
\hline
\end{tabular}


Adapun kesimpulan dari tabel di atas bahwa kolom "Ya" terdapat 26 centang atau $100 \%$. Jadi pada pelaksanaaan siklus II, guru lebih memaksimalkan dalam penggunaan metode dan cara penyampaian materi serta telah memperbaiki kelemahan dari siklus I.

c. Lembar Hasil Pengamatan Siswa Siklus II

Tabel 4.6Lembar Observasi Siswa

\begin{tabular}{|c|c|c|c|}
\hline \multirow[t]{2}{*}{ No } & \multirow[t]{2}{*}{ Aspek yang Diamati } & \multicolumn{2}{|c|}{ Skala Partisipasi } \\
\hline & & YA & TIDAK \\
\hline \multirow[t]{5}{*}{ A. } & \multicolumn{3}{|l|}{ Kegiatan Awal } \\
\hline & $\begin{array}{l}\text { 1. Siswa menjawab salam dengan semangat dan } \\
\text { dilanjutkan berdoa }\end{array}$ & $\sqrt{ }$ & \\
\hline & 2. Siswa merespon panggilan presensi dari guru & $\sqrt{ }$ & \\
\hline & 3. Siswa menjawab pertanyaan apersepsi dari guru & $\sqrt{ }$ & \\
\hline & $\begin{array}{l}\text { 4. Siswa mendengarkan penjelasan langkah-langkah } \\
\text { pembelajaran yang akan dilaksanakan }\end{array}$ & $\sqrt{ }$ & \\
\hline \multirow[t]{17}{*}{ B. } & \multicolumn{3}{|l|}{ Kegiatan Inti } \\
\hline & \multicolumn{3}{|l|}{ Eksplorasi } \\
\hline & $\begin{array}{l}\text { 5. Siswa memperhatikan penjelasan dari guru tentang } \\
\text { metode Cooperative Script dan Make A Match }\end{array}$ & $\sqrt{ }$ & \\
\hline & $\begin{array}{l}\text { 6. Siswa mendengarkan peraturan dan tata cara } \\
\text { pembelajaran yang akan dilaksanakan }\end{array}$ & $\sqrt{ }$ & \\
\hline & Elaborasi & & \\
\hline & $\begin{array}{l}\text { 7. Siswa secara berpasangan untuk mengkomunikasikan } \\
\text { materi }\end{array}$ & $\sqrt{ }$ & \\
\hline & 8. Siswa mengambil satu buah kartu yang telah disediakan & $\sqrt{ }$ & \\
\hline & 9. Setiap siswa mendapat satu buah kartu & $\sqrt{ }$ & \\
\hline & $\begin{array}{l}\text { 10. Setiap siswa memikirkan jawaban atas soal dari kartu } \\
\text { yang dipegang }\end{array}$ & $\sqrt{ }$ & \\
\hline & $\begin{array}{l}\text { 11. Setiap siswa mencari pasangan yang mempunyai kartu } \\
\text { yang cocok dengan kartunya }\end{array}$ & $\sqrt{ }$ & \\
\hline & $\begin{array}{l}\text { 12. Setiap siswa yang dapat mencocokkan kartunya } \\
\text { sebelum batas waktu diberi point }\end{array}$ & $\sqrt{ }$ & \\
\hline & $\begin{array}{l}\text { 13. Setiap siswa yang belum mendapatkan pasangan yang } \\
\text { sesuai dengan kartu maka diberi hukuman }\end{array}$ & $\sqrt{ }$ & \\
\hline & $\begin{array}{l}\text { 14. Siswa bersama pasangannnya mempresentasikan kartu } \\
\text { yang dipegang }\end{array}$ & $\sqrt{ }$ & \\
\hline & 15. Siswa mengerjakan soal yang diberikan oleh guru & $\sqrt{ }$ & \\
\hline & Konfirmasi & & \\
\hline & 16. Siswa berani mengajukan pertanyaan kepada guru & $\sqrt{ }$ & \\
\hline & 17. Siswa mengumpulkan lembar kerja & $\sqrt{ }$ & \\
\hline C. & Penutup & & \\
\hline & 18. Siswa menyimpulkan materi & $\sqrt{ }$ & \\
\hline & 19. Siswa berdoa dan menjawab salam & $\sqrt{ }$ & \\
\hline
\end{tabular}

Berdasarkan tabel tersebut bahwa kolom "Ya" terdapat 19 siswa atau 100\%.Hal ini menunjukkan bahwa pada siklus II terjadi peningkatan, pada siklus II siswa dapat lebih aktif dan tidak malu untuk menyampaikan aspirasi maupun bertanya. 


\section{KESIMPULAN}

Berdasarkan hasil penelitian dan pembahasan dapat disimpulkan bahwa melalui metode Cooperative Script dan Make A Match dapat meningkatkan hasil belajar siswa Pendidikan Agama Islam materi Iman kepada Malaikat-Malaikat Allah SWT pada siswa kelas VII G SMP Negeri 1 Salatiga.

Hal ini dibuktikan dari peningkatan pada setiap siklusnya. Pada kegiatan pra siklus siswa yang tuntas sebanyak 5 siswa dan dengan presentase ketuntasan 26,3\% .Pada kegiatan siklus I sebanyak 9 siswa dan dengan presentase ketuntasan 47,4\%.Pada kegiatan siklus II menjadi 17 siswa dan dengan presentase ketuntasan $89,5 \%$.

Dengan presentase ketuntasan $89,5 \%$ pada siklus II telah melampaui indikator ketuntasan secara klasikal yang telah ditetapkan yaitu $85 \%$. Maka siklus II ini telah dikatakan berhasil dengan menggunakan metode Cooperative Script dan Make A Match pada materi Iman kepada MalaikatMalaikat Allah SWT.

Peneliti selanjutnya diharapkan dapat mengembangkan hasil penelitian ini sehingga penelitian yang belum sempurna ini dapat menjadi lebih baik dan bermanfaat bagi dunia pendidikan kita, khusuusnya pendidikan Sekolah Menengah Pertama.

\section{DAFTAR PUSTAKA}

[1] Arikunto, Suharsimi. dkk. Penelitian Tindakan Kelas. Jakarta: PT Bumi Aksara. 2015: hlm. 1.

[2] Hidayati, Lili. Kurikulum 2013 dan Arah Baru Pendidikan Agama Islam. Insania. 2014: Vol. 19, No. 1, Januari-Juni.hlm. 77.

[3] Rahyubi, Heri.Teori-Teori Belajar dan Aplikasi Pembelajaran Motorik. Jawa Barat: Referens. 2014: hlm. 4.

[4] Rohyani, Ema Siti.Pemikiran Pendidikan Agama Islam dalam Perspektif Prof. Achmadi. "Mudarrisa: Jurnal Kajian Pendidikan Islam". 2015: Vol. 7, No.2, Desember. hlm. 178

[5] Suprihatiningrum, Jamil. Strategi Pembelajaran: Teori dan Aplikasi. Jogjakarta: R-Ruzz Media. 2017: hlm. 14.

[6] Sutrisno. Berbagai Pendekatan dalam Pendidikan Nilai dan Pendidikan Kewarganegaraan. Jurnal Dimensi Pendidikan dan Pembelajaran. 2016. Vol. 5 Januari.hlm. 30.

[7] Wiriaatmadja, Rochiati. 2009. Metode Penelitian Tindakan Kelas. Bandung: PT Remaja Rosdakarya.

[8] Yamin, Mohammad. Teori dan Metode Pembelajaran: Konsepsi, Strategi dan Pratik Belajar yang Membangun Karakter. Jawa Timur: Madani. 2014. hlm. 7.

[9] Zaman, Badrus. Pendidikan Akhlak pada Anak Jalanan di Surakarta. Jurnal Inspirasi Undaris Ungaran 2018: Vol. 2 No. 2. hlm. 130

[10] Zaman, Badrus. Urgensi Pendidikan Karakter yang sesuai dengan Falsafah Bangsa Indonesia. Jurnal Al Ghazali STAINU Purworejo. 2019: Vol. 2 No. 1. hlm. 19-20. 